\title{
Thermodynamically Rigorous Description of the Open Circuit Voltage of Redox Flow Batteries
}

To cite this article before publication: Nicolas Hayer et al $2020 \mathrm{~J}$. Electrochem. Soc. in press https://doi.org/10.1149/1945-7111/ab9e85

\section{Manuscript version: Accepted Manuscript}

Accepted Manuscript is "the version of the article accepted for publication including all changes made as a result of the peer review process, and which may also include the addition to the article by IOP Publishing of a header, an article ID, a cover sheet and/or an 'Accepted

Manuscript' watermark, but excluding any other editing, typesetting or other changes made by IOP Publishing and/or its licensors"

This Accepted Manuscript is $\odot 2020$ The Author(s). Published by IOP Publishing Ltd..

This article can be copied and redistributed on non commercial subject and institutional repositories.

Although reasonable endeavours have been taken to obtain all necessary permissions from third parties to include their copyrighted content within this article, their full citation and copyright line may not be present in this Accepted Manuscript version. Before using any content from this article, please refer to the Version of Record on IOPscience once published for full citation and copyright details, as permissions will likely be required. All third party content is fully copyright protected, unless specifically stated otherwise in the figure caption in the Version of Record.

View the article online for updates and enhancements. 


\section{Thermodynamically Rigorous Description of the Open Circuit Voltage of Redox Flow Batteries}

\begin{tabular}{|r|l|}
\hline Journal: & Journal of The Electrochemical Society \\
\hline Manuscript ID & JES-101200.R2 \\
\hline Manuscript Type: & Research Paper \\
\hline Author: & 16 -Jun-2020 \\
\hline Complete List of Authors: & $\begin{array}{l}\text { Hayer, Nicolas; Technische Universität Kaiserslautern, Laboratory of } \\
\text { Engineering Thermodynamics } \\
\text { Kohns, Maximilian; Technische Universität Kaiserslautern, Laboratory of } \\
\text { Engineering Thermodynamics }\end{array}$ \\
\hline Keywords: & $\begin{array}{l}\text { Vanadium redox flow battery, Iron-cadmium redox flow battery, Open } \\
\text { circuit voltage, Nernst equation, Pitzer model, Thermodynamics }\end{array}$ \\
\hline
\end{tabular}

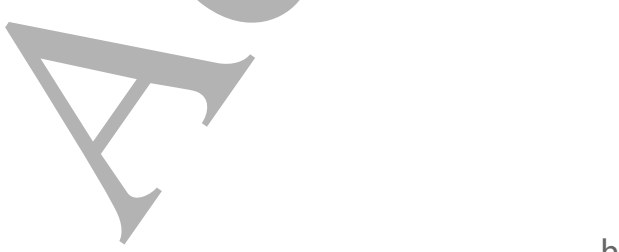




\title{
Thermodynamically rigorous description of the
} open circuit voltage of redox flow batteries

\begin{abstract}
Nicolas Hayer ${ }^{1}$ and Maximilian Kohns ${ }^{1}$
${ }^{1}$ Technische Universität Kaiserslautern (TUK), Laboratory of Engineering Thermodynamics (LTD), Erwin-Schrödinger Straße 44, 67663 Germany

E-mail: maximilian.kohns@mv.uni-kl.de

April 2020

Abstract. Redox flow batteries (RFBs) are considered an outstanding candidate for the integration of renewable energy sources into the existing power grids. A key property of RFBs is the open circuit voltage (OCV) corresponding to the currentless equilibrium state. In the literature, the Nernst equation describing this property is often simplified by neglecting the activity coefficients. In this work, using a thermodynamically rigorous approach, we show that activity coefficients have a significant influence on the OCV of the Iron-Cadmium and AllVanadium RFBs. Moreover, this influence varies with the state of charge. Therefore, activity coefficients should not be neglected in the Nernst equation. We show that when doing so, the resulting offset in OCV is actually comparable to typical voltage losses occurring during operation. Hence, fitting kinetic parameters to measurement data of voltage losses can lead to ambiguous results if only the idealized OCV, obtained by neglecting the activity coefficients, is used in that evaluation. Therefore, the implementation of a thermodynamically rigorous model has the potential to significantly improve state-of-the-art models for RFBs.
\end{abstract}

Keywords: Vanadium redox flow battery, Iron-cadmium redox flow battery, Open circuit voltage, Nernst equation, Pitzer model 
Thermodynamically rigorous description of the $O C V$ of $R F B s$

\section{Introduction}

Renewable energy sources are currently the fastest growing sources of electricity generation in the world. It is predicted that by 2040 their share will be equivalent to that of coal [1]. In contrast to conventional power plants, renewable energy sources such as solar and wind power are intermittent, as the resources are not continuously available for conversion into electricity due to temporal and climatic conditions. Therefore, a stable implementation into the existing power grids is difficult and requires the use of electrical energy storage (EES) systems [2]. Redox flow batteries (RFBs) are considered an outstanding candidate among the existing EES systems for stationary energy storage in the grid area, as they offer significant advantages over competing systems (e.g. batteries and supercapacitors), such as independent scaling of power and capacity [2, 3].

In the 1970s, the Iron-Chromium RFB (Fe/Cr RFB), which is considered the first redox flow battery, was invented and primarily developed by NASA [4]. In 1985 the investigations of Sum et al. on the application of the $\mathrm{V}$ (II)/V(III) redox pair in the negative half-cell and the $\mathrm{V}(\mathrm{IV}) / \mathrm{V}(\mathrm{V})$ redox pair in the positive halfcell of an RFB were published [5, 6]. As a consequence, first patents were filed for the All-Vanadium RFB (AVRFB) a few years later. These expired in 2006, which has resulted in renewed interest in commercializing the technology. At present, the AVRFB is the most widely used RFB for large-scale energy storage [7]. Several applications already exist, with power outputs ranging from $2 \mathrm{~kW}$ to $50 \mathrm{MW}$ and energy capacities from $30 \mathrm{kWh}$ to $250 \mathrm{MWh}$ [8]. In recent years, different surface treatments and catalysts were applied to the AVRFB electrodes to increase their reactivity towards redox reactions [9]. The main reason for the popularity of the AVRFB is its unique characteristic that all species involved in the redox reactions of both half-cells are vanadium ions. Thus, in contrast to most other RFBs, cross contamination is effectively eliminated [10]. In the case of other RFBs, such as the $\mathrm{Fe} / \mathrm{Cr} \mathrm{RFB}$, dedicated attempts are made to minimize cross contamination by using mixed electrolyte solutions in both half-cells [11. The main disadvantage of the AVRFB is the high cost of vanadium salts. The vanadium in the electrolyte solution accounts for $30-60 \%$ of total system costs [8].

Current research on RFBs focuses on increasing energy efficiency and longterm stability, while reducing material and operating costs. There are many design parameters, including e.g. the choice and composition of the electrolyte 
solution, the electrode and membrane materials, the cell geometry, and flow conditions [4, 12, 13, 14, 15], so that an accurate mathematical modeling plays a key role in understanding and optimizing RFBs. The employed models differ in their complexity and therefore the computational cost, ranging from simple zerodimensional [16, 17, 18] to one- [19, 20] and two-dimensional [21, 22, 23] to elaborate and numerically intensive three-dimensional models [24, 25]. However, in most studies only the AVRFB is considered, since its development is most advanced compared to other RFB types.

A key objective in modeling RFBs is the cell voltage. It can be calculated from the Nernst equation describing the open circuit voltage (OCV) at electrochemical equilibrium and adding terms for voltage losses. These losses consist of ohmic losses and overpotentials (e.g. activation overpotential, reaction overpotential or concentration overpotential) [26]. Recent models of RFBs differ in their treatment of the overpotentials [16, 17, 18]. For example, the equation for the calculation of the cell voltage $E_{\text {cell }}$ used in the zero-dimensional model according to Sharma et al. [17] is

$$
E_{\text {cell }}=E_{\text {cell, real }}^{\text {rev }}+E_{\text {losses }}=E_{\text {cell, real }}^{\text {rev }}+\sum_{k}\left(\eta_{k}^{\text {ohm }}\right)+\eta_{\text {pos }}^{\text {act }}+\eta_{\text {neg }}^{\text {act }} .
$$

Here, $E_{\text {cell, real }}^{\text {rev }}$ is the OCV calculated from the Nernst equation (see below), $\eta_{k}^{\text {ohm }}$ are ohmic losses in different parts $k$ of the RFB (e.g. membrane, electrolyte, current collectors), and $\eta_{\text {pos }}^{\text {act }}$ and $\eta_{\text {neg }}^{\text {act }}$ are activation overpotentials in the positive and negative electrodes, respectively. It is obvious that when adjusting model parameters for the loss terms in Eq. (1) to measurement data for $E_{\text {cell }}$, the outcome depends on how the OCV is calculated. In general, the OCV depends only on the reacting redox pair, the overall composition of the electrolyte solution, and the temperature [27]. In contrast, the voltage losses $E_{\text {losses }}$ are also influenced by the design of the RFB (cell geometry, flow conditions, electrode and membrane materials).

The OCV of a RFB can be calculated using the Nernst equation, which is given by

$$
\begin{aligned}
E_{\text {cell }, \text { real }}^{\text {rev }} & =E_{\text {cell }}^{0}-\frac{R T}{z F} \ln \prod_{i=1}^{N} a_{i}^{\nu_{i}} \\
& =E_{\text {cell }}^{0}-\frac{R T}{z F} \ln \prod_{i=1}^{N}\left(\frac{b_{i}}{b^{0}}\right)^{\nu_{i}}-\frac{R T}{z F} \ln \prod_{i=1}^{N}\left(\gamma_{i}^{b *}\right)^{\nu_{i}},
\end{aligned}
$$


where $E_{\text {cell }}^{0}$ is the standard cell potential, $R$ is the universal gas constant, $T$ is the temperature, $z$ is the number of electrons transferred in the cell reaction, $N$ is the number of components of the cell reaction, and $b^{0}=1 \mathrm{~mol} \mathrm{~kg}^{-1}$ is the unit molality. Furthermore, $a_{i}, b_{i}, \gamma_{i}^{b *}$, and $\nu_{i}$ are the activity, molality, activity coefficient on the molality scale, and stoichiometric coefficient of component $i\left(\nu_{i}>0\right.$ for products and $\nu_{i}<0$ for reactants), respectively.

The correct application of the Nernst equation to RFBs has been the subject of substantial debate in the literature. There were even discussions which species should be considered in Eq. (21). As an example, when modeling AVRFBs it was common to neglect the proton molalities [21, 28, 29], until Knehr and Kumbur 30] and Gandomi et al. [31] stressed that this approach is invalid. From a thermodynamic standpoint, however, it is clear that all species taking part in the half-cell reactions must appear in the Nernst equation.

Moreover, it is common practice in the literature to neglect the activity coefficients $\gamma_{i}^{b *}$ of the species that appear in the Nernst equation, i.e. setting $\gamma_{i}^{b *}=1$ for all $i$, although highly concentrated, multicomponent aqueous electrolyte solutions are usually employed in RFBs. Lenihan et al. [10] estimate the water activity of electrolyte solutions employed in AVRFBs to be in the range $0.6-0.8$, which corresponds to a highly non-ideal solution. To the best of our knowledge, only Muñoz et al. 32] emphasize the importance of activity coefficients for a more accurate prediction of the OCV. They introduce a 'global activity coefficient' as a correction to the neglect of the activity coefficients of the individual species, which, however, can only be determined by fitting to measurement data. In several studies, the collective effect of the activity coefficients is combined into a so-called 'formal potential term', commonly measured at state of charge (SOC) of 50\% [33, 34, 35]. However, activity coefficients in electrolyte solutions are very sensitive to the concentration. This has two consequences: First, the 'formal potential term' must be measured whenever the initial composition of the electrolyte solution is changed. This is important e.g. when studying different concentrations of the vanadium species or testing a different supporting electrolyte. Second, and more importantly, the results of the present work show that the 'formal potential term' actually changes with the SOC. Therefore, it cannot be simply added to the standard cell potential as a constant offset.

Hence, the central aspect of the present work will be the last term in Eq. (2). Since it considers the influence of activity coefficients on the OCV and thus stems from the excess chemical potential, that term will be called 'excess OCV' from here 
on and designated with the symbol $E_{\text {ex }}$. It is defined as

$$
E_{\mathrm{ex}}=-\frac{R T}{z F} \ln \prod_{i=1}^{N}\left(\gamma_{i}^{b *}\right)^{\nu_{i}} .
$$

Denoting the two remaining terms in Eq. (2) by $E_{\text {cell, ideal }}^{\mathrm{rev}}$ yields

$$
E_{\text {cell, real }}^{\text {rev }}=E_{\text {cell, ideal }}^{\text {rev }}+E_{\text {ex }} \text {. }
$$

In this work, a model for the exact prediction of the OCV for different RFB types is developed, focusing mainly on the Iron-Cadmium RFB (Fe/Cd RFB). The reason for this choice is that a reliable thermodynamic model for this electrolyte system is available in the literature, namely the Pitzer model. Unfortunately, a thermodynamically rigorous model cannot be built in the same way for the AVRFB due to a lack of necessary model parameters or data from which these parameters could be obtained. Nevertheless, based on experimental data of the OCV of an AVRFB from the literature, the influence of the activity coefficients on the OCV over the SOC can be determined. Additionally, the developed model is used to investigate the sensitivity of the OCV on the composition of the electrolyte solution of the Fe/Cd RFB, again comparing the ideal' (all $\gamma_{i}^{b *}=1$ ) to the 'real' ( $\gamma_{i}^{b *}$ from a thermodynamic model) treatment. Furthermore, voltage losses during operation of the RFB are investigated using measurement data and existing models from the literature.

This work is organized as follows: The considered RFB types and the proposed model for the OCV calculation is explained in the Model development section. Following this, an overview of the scenarios studied in the present work is given in the Simulation section. The findings obtained from these scenarios are then discussed in the Results and Discussion section, before conclusions are drawn. The supplementary material contains some technical details of the calculations and an overview of electrochemical thermodynamics for the reader's reference. A more detailed review of the latter was recently given in ref. [36]. 
Thermodynamically rigorous description of the OCV of RFBs

\section{Model development}

Considered RFB types

Overview

As there are many articles in which the functionality of RFBs is described excellently, e.g. ref. [34], we refrain from including such a description here. In this work, two types of RFBs were investigated, namely the AVRFB and the Fe/Cd RFB. In addition, two different compositions of the electrolyte solutions were considered for the Fe/Cd RFB. The main purpose of the developed mathematical model is the accurate calculation of the OCV of these RFBs. However, the methodology can be easily applied to other RFB types, given that all necessary parameters are available. We note here that only those reactions which are explicitly given in the text are included in the model. Side reactions are neglected and would otherwise have to be implemented in the model in the same way as the considered ones. Furthermore, we assume that all electrolyte solutions are well mixed to attain the state of equilibrium.

\section{$A V R F B$}

In the case of the AVRFB, the positive electrolyte solution tank contains $\mathrm{VO}_{2}^{+}$ and $\mathrm{VO}^{2+}$ ions and the negative electrolyte solution tank contains $\mathrm{V}^{3+}$ and $\mathrm{V}^{2+}$ ions, which corresponds to vanadium in the oxidation states $\mathrm{V}, \mathrm{IV}$, III, and II. In addition, a supporting acid, which is typically sulfuric acid for the AVRFB, is added to increase the solubility of the salts and the conductivity of the electrolyte solution. The chemical reactions on the electrodes of the two half-cells and their potential vs. the standard hydrogen electrode (SHE) can be expressed as [37] 


\section{$\mathrm{Fe} / \mathrm{Cd} \mathrm{RFB}$}

$$
\begin{gathered}
\mathrm{VO}_{2 \text { pos }}^{+}+2 \mathrm{H}_{\text {pos }}^{+}+\mathrm{V}_{\text {neg }}^{2+} \underset{\text { charge }}{\stackrel{\text { discharge }}{\rightleftharpoons}} \mathrm{VO}_{\text {pos }}^{2+}+\mathrm{H}_{2} \mathrm{O}_{\text {pos }}+\mathrm{V}_{\text {neg }}^{3+} \\
E_{\text {cell }}^{0}=1.256 \mathrm{~V} \text { vs. SHE. }
\end{gathered}
$$

Combining the reactions (II) and (II) leads to the total cell reaction of the AVRFB:

In addition to the established RFBs, the combination of different half-cell reactions and variations in the composition of the electrolyte solutions result in a very large number of other possible RFB designs. A new promising candidate is the $\mathrm{Fe} / \mathrm{Cd} \mathrm{RFB}$ developed by Zeng et al. [38], which showed a small capacity reduction during the cycle test and low predicted costs for energy storage. In contrast to the AVRFB, the same initial electrolyte solution, which is an aqueous solution of $\mathrm{FeCl}_{2}$ and $\mathrm{CdCl}_{2}$ with $\mathrm{HCl}$ as the supporting acid, is typically used in both half-cells. The cell is equipped with a cation exchange membrane through which only $\mathrm{H}^{+}$can diffuse. The $\mathrm{Fe} / \mathrm{Cd}$ RFB is a hybrid RFB, i.e. a solid is formed during charging: at the negative electrode, cadmium metal is dissolved and redeposited. The chemical reactions occurring in the half-cells of the Fe/Cd RFB can be expressed as [38]

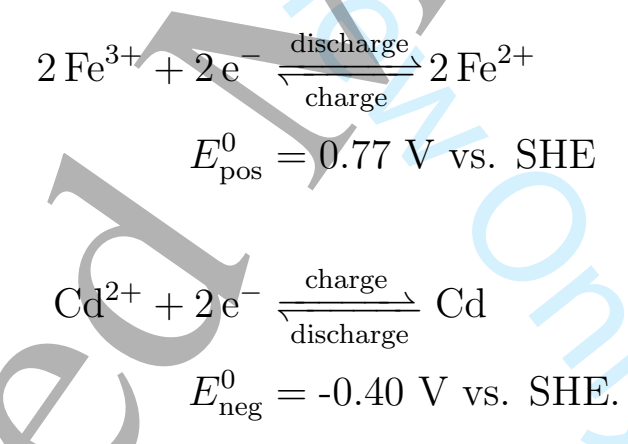

Combining the reactions (IV) and (V) leads to the total cell reaction of the $\mathrm{Fe} / \mathrm{Cd}$ RFB:

$$
\begin{gathered}
2 \mathrm{Fe}_{\text {pos }}^{3+}+\mathrm{Cd}_{\text {neg }} \underset{\text { charge }}{\stackrel{\text { discharge }}{\rightleftharpoons}} 2 \mathrm{Fe}_{\text {pos }}^{2+}+\mathrm{Cd}_{\text {neg }}^{2+} \\
E_{\text {cell }}^{0}=1.17 \mathrm{~V} \text { vs. SHE. }
\end{gathered}
$$


Thermodynamically rigorous description of the $O C V$ of $R F B s$

Mass balance

Overview

The properties of RFBs are usually described as a function of the SOC. Throughout the present work, the SOC is defined as

$$
\mathrm{SOC}=\frac{b_{\mathrm{Me}, \mathrm{ox}}^{\mathrm{pos}}}{b_{\mathrm{Me}, \mathrm{ox}}^{\text {pos }}+b_{\mathrm{Me}, \mathrm{red}}^{\text {pos }}}=\frac{b_{\mathrm{Me}, \mathrm{ox}}^{\mathrm{pos}}}{b_{\mathrm{Me}, \mathrm{tot}}^{\mathrm{pos}}},
$$

where $b_{\mathrm{Me}, \mathrm{px}}^{\mathrm{pos}}$ represents the molality of the active metal species (Me) in the positive half-cell (pos) in oxidized form and $b_{\mathrm{Me}, \mathrm{ped}}^{\text {os }}$ in reduced form. Hence, an SOC of 1 corresponds to a fully charged RFB, and an SOC of 0 corresponds to a fully discharged RFB. It is also possible to define the $\mathrm{SOC}$ with respect to the molalities in the negative half-cell, which leads to an expression equivalent to Eq. (5). In the literature, sometimes molarities are used to define the SOC instead of molalities [18, 20].

Furthermore, for both RFBs considered in this work, the following mass balances, which can be derived from Eq. (5), are applicable:

$$
\begin{aligned}
b_{\mathrm{Me}, \mathrm{ox}}^{\mathrm{pos}} & =\mathrm{SOC} \cdot b_{\mathrm{Me}, \mathrm{tot}}^{\mathrm{pos}} \\
b_{\mathrm{Me}, \mathrm{red}}^{\mathrm{pos}} & =(1-\mathrm{SOC}) \cdot b_{\mathrm{Me}, \mathrm{tot}}^{\mathrm{pos}} \\
b_{\mathrm{Me}, \mathrm{ox}}^{\mathrm{neg}} & =(1-\mathrm{SOC}) \cdot b_{\mathrm{Me}, \mathrm{tot}}^{\mathrm{neg}} \\
b_{\mathrm{Me}, \mathrm{red}}^{\mathrm{neg}} & =\mathrm{SOC} \cdot b_{\mathrm{Me}, \mathrm{tot}}^{\mathrm{neg}} \cdot
\end{aligned}
$$

An additional necessary assumption for the derivation of Eqs. (8) and (9) is

$$
n_{\mathrm{Me}, \mathrm{tot}}^{\mathrm{pos}} \cdot z_{\mathrm{pos}}=n_{\mathrm{Me}, \mathrm{tot}}^{\mathrm{neg}} \cdot z_{\mathrm{neg}}
$$

where $n_{\mathrm{Me} \text {,tot }}^{\mathrm{pos}}$ and $n_{\mathrm{Me} \text {,tot }}^{\mathrm{neg}}$ are the total number of moles of the active metal species in the positive and negative half-cells. Furthermore, $z_{\text {pos }}$ and $z_{\text {neg }}$ are the numbers of electrons transferred per mole of metal species in the positive and negative halfreaction, respectively. Eq. 10 is valid for all the compositions of the electrolyte solutions described in this work (see Table 1) and ensures that the capacity of both half-cells is the same. Therefore, at an SOC of 0 and 1, only one species of the corresponding redox couple is present in both the positive and negative half-cells. In the case of the two RFBs considered in this work, Eq. 10 leads to

$$
n_{\mathrm{V}, \text { tot }}^{\text {pos }}=n_{\mathrm{V}, \text { tot }}^{\mathrm{neg}}
$$


Thermodynamically rigorous description of the $O C V$ of $R F B s$

for the AVRFB and

$$
n_{\mathrm{Fe}, \text { tot }}^{\text {pos }}=2 \cdot n_{\mathrm{Cd}, \text { tot }}^{\text {neg }}
$$

for the Fe/Cd RFB.

All salts are assumed to dissociate completely. Furthermore, it is assumed that hydrochloric acid dissociates completely according to

$$
\mathrm{HCl} \longrightarrow \mathrm{H}^{+}+\mathrm{Cl}^{-} \text {. }
$$

In the case of sulfuric acid, only the first dissociation step is considered to be complete, while the incomplete dissociation of bisulfate is captured via its dissociation equilibrium constant:

$$
\begin{gathered}
\mathrm{H}_{2} \mathrm{SO}_{4} \longrightarrow \mathrm{H}^{+}+\mathrm{HSO}_{4}^{-} \\
\mathrm{HSO}_{4}^{-} \rightleftharpoons \mathrm{H}^{+}+\mathrm{SO}_{4}^{2-}
\end{gathered}
$$

The thermodynamic equilibrium constant of reaction $\mathrm{IX}\left(K_{\mathrm{a}}=1.05 \cdot 10^{-2}\right.$ at $298.15 \mathrm{~K}$ and 1 bar) is taken from the literature [39]. More details on the calculation of this dissociation equilibrium are provided in the supplementary material.

\section{AVRFB}

In case of the AVRFB, the SOC (see Eq. (5)) is defined as

$$
\mathrm{SOC}=\frac{b_{\mathrm{VO}_{2}^{+}}^{\mathrm{pos}}}{b_{\mathrm{VO}_{2}^{+}}^{\mathrm{pos}}+b_{\mathrm{VO}^{2+}}^{\mathrm{pos}}}=\frac{b_{\mathrm{VO}}^{\mathrm{pos}}}{b_{\mathrm{V}, \mathrm{tot}}^{\mathrm{pos}}}
$$

By applying Eqs. (6) - (9) to an AVRFB with cation exchange membrane, in which protons diffuse freely between the two half-cells, Eqs. (14) - (17) are obtained. 
In addition to the metal ions, the molality of the protons in the two half-cells is crucial for the calculations. During operation of the RFB, this molality yaries and is influenced by $b_{\mathrm{H}^{+}}$,add, which represents the amount of additional protons due to redox reactions and diffusion through the membrane. In the positive half-cell, two moles of protons are formed per mole of $\mathrm{VO}_{2}^{+}$during charging (see reaction (II)). At the same time, one mole of protons diffuses through the cation exchange membrane into the negative half-cell. Here, $b_{\mathrm{H}^{+}}$,add is defined relative to a fully discharged RFB $(\mathrm{SOC}=0)$. Of course, the actual proton concentration also depends on the overall acid concentration and the dissociation equilibrium of the corresponding acid (see reactions (VII) - (IX) .

Water is formed in the positive half-cell of the AVRFB during discharge. The mass balance of water in this case can be expressed as

$$
m_{\mathrm{W}}^{\mathrm{pos}}=m_{\mathrm{W}, \mathrm{SOC}=0}^{\mathrm{pos}}-b_{\mathrm{VO}_{2}^{+}}^{\mathrm{pos}} \cdot m_{\mathrm{W}}^{\mathrm{pos}} \cdot M_{\mathrm{W}},
$$

where $m_{\mathrm{W}, \text { SOC=0 }}^{\text {pos }}$ is the mass of water in the positive half-cell at an SOC of 0 and $M_{\mathrm{W}}$ is the molar mass of water. Inserting Eq. (14) into Eq. (201) and rearranging yields

$$
m_{\mathrm{W}}^{\mathrm{pos}}=\frac{m_{\mathrm{W}, \mathrm{SOC}=0}^{\mathrm{pos}}}{1+\mathrm{SOC} \cdot b_{\mathrm{V}, \mathrm{tot}}^{\mathrm{pos}} \cdot M_{\mathrm{W}}} .
$$

In the case of an AVRFB setup with an anion exchange membrane, $\mathrm{HSO}_{4}^{-}$ions instead of protons can diffuse freely between the two half-cells. Therefore, in this case, Eq. (18) and (19) have to be replaced by the following relationships:

$$
\begin{aligned}
b_{\mathrm{H}^{+}, \text {add }}^{\mathrm{pos}} & =+2 b_{\mathrm{vO}_{2}^{+}}^{\mathrm{pos}} \\
b_{\mathrm{HSO}_{4}^{-}, \text {add }}^{\mathrm{pos}} & =+b_{\mathrm{VO}_{2}^{+}}^{\mathrm{pos}^{\mathrm{nog}}} \\
b_{\mathrm{HSO}_{4}^{-}, \text {add }}^{\text {neg }} & =-b_{\mathrm{V}^{2+}}^{\mathrm{neg}}
\end{aligned}
$$

$\mathrm{Fe} / \mathrm{Cd} \mathrm{RFB}$

In case of the $\mathrm{Fe} / \mathrm{Cd} \mathrm{RFB}$, the SOC is defined as

$$
\mathrm{SOC}=\frac{b_{\mathrm{Fe}^{3+}}^{\mathrm{pos}}}{b_{\mathrm{Fe}^{3+}}^{\mathrm{pos}}+b_{\mathrm{Fe}^{2+}}^{\mathrm{pos}}}=\frac{b_{\mathrm{Fe}}^{\mathrm{pos}}}{b_{\mathrm{Fe}, \mathrm{tot}}^{\mathrm{pos}}} .
$$


By applying Eqs. (6) - 9) to an Fe/Cd RFB with cation exchange membrane, the following mass balances are obtained:

$$
\begin{aligned}
b_{\mathrm{Fe}^{3+}}^{\mathrm{pos}} & =\mathrm{SOC} \cdot b_{\mathrm{Fe}, \text { tot }}^{\mathrm{pos}} \\
b_{\mathrm{Fe}^{2+}}^{\text {pos }} & =(1-\mathrm{SOC}) \cdot b_{\mathrm{Fe}, \text { tot }}^{\text {pos }} \\
b_{\mathrm{Cd}}^{\text {neg }} & =(1-\mathrm{SOC}) \cdot b_{\mathrm{Cd}, \text { tot }}^{\text {neg }} \\
b_{\mathrm{Cd}}^{\text {neg }} & =\mathrm{SOC} \cdot b_{\mathrm{Cd}, \text { tot }}^{\text {neg }} \\
b_{\mathrm{H}^{+}, \text {add }}^{\text {pos }} & =-b_{\mathrm{Fe}^{3+}}^{\text {pos }} \\
b_{\mathrm{H}^{+}, \text {add }}^{\text {neg }} & =2 b_{\mathrm{Cd}}^{\text {neg }} .
\end{aligned}
$$

Since diffusion of water across the membrane is neglected, a constant amount of solvent can be assumed for the Fe/Cd RFB with the result that $b_{\mathrm{Fe}, \text { tot }}^{\mathrm{pos}}$ and $b_{\mathrm{Cd} \text {,tot }}^{\text {neg }}$ always equal their initial values. This assumption is not yalid for the AVRFB due to the formation of water at the positive half-cell during discharge.

\section{Nernst equation}

For the Fe/Cd RFB, the Nernst equation was derived in the present work (see Appendix) and is given by

$$
\begin{aligned}
E_{\text {cell, real }}^{\text {rev }} & =E_{\text {cell }}^{0}+\frac{R T}{2 F} \ln \left(\frac{\left(a_{\mathrm{Fe}^{3+}+}^{\text {pos }}\right)^{2}\left(a_{\mathrm{H}^{+}}^{\text {neg }}\right)^{2} a_{\mathrm{Cd}}^{\text {neg }}}{\left(a_{\mathrm{Fe}^{2+}}^{\text {pos }}\right)^{2}\left(a_{\mathrm{H}^{+}}^{\text {pos }}\right)^{2} a_{\mathrm{Cd}^{2+}}^{\text {neg }}}\right) \\
\text { with } E_{\text {cell }}^{0} & =1.17 \mathrm{~V} .
\end{aligned}
$$

For the AVRFB, the Nernst equation was derived by Pavelka et al. [37]. In case of a cation exchange membrane, it is given by

$$
\begin{aligned}
E_{\text {cell, real }}^{\text {rev }} & =E_{\text {cell }}^{0}+\frac{R T}{F} \ln \left(\frac{a_{\mathrm{VO}_{2}^{+}}^{\text {pos }} a_{\mathrm{V}^{2+}}^{\text {neg }} a_{\mathrm{H}^{+}}^{\text {pos }} a_{\mathrm{H}^{+}}^{\text {neg }}}{a_{\mathrm{VO}^{2+}}^{\text {pos }} a_{\mathrm{V}^{3+}}^{\text {neg }} a_{\mathrm{H}_{2} \mathrm{O}}^{\text {pos }}}\right) \\
\text { with } E_{\text {cell }}^{0} & =1.256 \mathrm{~V})
\end{aligned}
$$

If an anion exchange membrane is used in an AVRFB instead of the cation exchange membrane, Eq. (33) is replaced by

$$
\begin{aligned}
& E_{\text {cell, real }}^{\text {rev }}=E_{\text {cell }}^{0}+\frac{R T}{F} \ln \left(\frac{a_{\mathrm{VO}}^{\mathrm{pos}} a_{\mathrm{V}^{2+}}^{\mathrm{neg}}\left(a_{\mathrm{H}^{+}}^{\mathrm{pos}}\right)^{2} a_{\mathrm{HSO}_{4}^{-}}^{\mathrm{pos}}}{a_{\mathrm{VO}^{2+}}^{\text {pos }} a_{\mathrm{V}^{3+}}^{\text {ngg }} a_{\mathrm{H}_{2} \mathrm{O}}^{\mathrm{pos}} a_{\mathrm{HSO}_{4}^{-}}^{\text {neg }}}\right) \\
& \text { with } E_{\text {cell }}^{0}=1.256 \mathrm{~V} .
\end{aligned}
$$


Thermodynamically rigorous description of the $O C V$ of $R F B s$

\section{Activity coefficient model}

The investigated RFBs employ electrolyte solutions with high concentrations of salts and acids. A suitable thermodynamic model must be chosen for describing these solutions appropriately. In the present work, the Pitzer model is applied, which was implemented as suggested by Bea et al. [40]. In the literature, there is a plethora of models for activity coefficients in electrolyte solutions, which differ in their complexity and the number of adjustable parameters. In this work, the Pitzer model [41, 42, 43, 44, 45] is used to describe the activity coefficients, as it was developed especially for aqueous multicomponent solutions and has proven to yield reliable predictions at high ionic strengths [46]. All necessary model parameters for the simulations conducted in this work are taken from the literature and listed in the supplementary material. When selecting the parameters, care was taken to ensure that the concentrations used in the RFBs do not exceed the maximum molality of the parameterization data. Typically, Pitzer parameters are only available for room temperature $\left(25^{\circ} \mathrm{C}\right)$, which must be taken into account.

The composition of the electrolyte solution is frequently reported in molarities. However, since the Pitzer model is formulated in molalities, a conversion of the concentrations is necessary. For this purpose, overall molarities were converted into molalities using the formulae and tabulated data given in the supplementary material.

\section{Simulation}

The model described in the previous section was implemented in MATLAB $^{\circledR}$ R2018a [47]. Using the mass balances, dissociation equilibria, the Pitzer model, and the Nernst equation described therein, the OCV was calculated. The temperature and the overall composition of the electrolyte solution are necessary as input variables. Many of the input parameters of the model depend on temperature, e.g. the standard electrode potentials $E_{\text {cell }}^{0}$, the dissociation constants $K_{\mathrm{a}}$, and the Pitzer parameters (see supplementary material). All calculations in the present work are carried out for $298.15 \mathrm{~K}$. By selecting suitable input data, the developed model can be used to investigate many further RFB types and state conditions.

An overview of the simulations carried out in the present work is presented in Table 1. together with an overview of the RFB setups and Pitzer parameter sets. The electrolyte compositions were chosen according to experimental studies available 
in the literature [37, 38]. In addition, the sensitivity of OCV of the Fe/Cd RFB with respect to the overall composition of the electrolyte solution was investigated.

[Table 1 about here.]

To provide an insight into the reasoning behind the choice of studied scenarios, these scenarios are discussed in the following with respect to their objectives. The currentless state of equilibrium, i.e. the modeling of the OCV, is considered in scenarios $\# 1, \# 2$, and $\# 3$. In these scenarios, both the ideal $\left(\gamma_{i}^{b *}=1\right)$ and the real case $\left(\gamma_{i}^{b *}\right.$ from a thermodynamic model) were studied and compared. The compositions of the electrolyte solutions are taken from experimental investigations of the different RFBs from the literature (Zeng et al. [38] for the Fe/Cd RFB and Pavelka et al. [37] for the AVRFB). For the Fe/Cd RFBs, the overall compositions of the electrolyte solutions are usually the same in both half-cells to minimize the risk of cross contamination.

After the evaluation of the results with the typical overall molarities for the $\mathrm{Fe} / \mathrm{Cd} \mathrm{RFB}$ discussed in scenario \#1, the sensitivity of the OCV to variations in the composition of the electrolyte solution was investigated in scenario \#3. Again, the ideal and real cases were studied and compared. In scenario \#3, the overall molarity of hydrochloric acid was varied between 1.0 and $5.0 \mathrm{~mol} \mathrm{l}^{-1}$ (typical value: $3.0 \mathrm{~mol} \mathrm{l}^{-1}[38]$ ) and that of iron chloride was varied between 0.1 and $3.0 \mathrm{~mol} \mathrm{l}^{-1}$ (typical value: $1.0 \mathrm{~mol} \mathrm{l}^{-1}[38]$ ). The overall $\mathrm{CdCl}_{2}$ molarity was always half that of $\mathrm{FeCl}_{2}$. In experiments on stability of electrolyte solutions, Zeng et al. [38] showed that a composition with chloride salts only is less stable than a composition with sulfate salts and tends to form solid precipitates at higher overall metal concentrations (twice as high as in scenario \#1 in Table 1). At the higher electrolyte concentrations considered in the sensitivity analysis, precipitation might occur. However, this was not further investigated in the present work. All electrolyte solutions were assumed to be stable. Scenario \#4 is used to evaluate typical voltage losses that occur during operation of the RFB. Measurement data of the cell voltage of a Fe/Cd RFB were examined and compared with the simulation results of the OCV.

In the following, the studied scenarios are briefly discussed with respect to the availability of Pitzer parameters. The electrolyte solution for the Fe/Cd RFB with chloride salts only studied in scenario \#1 was chosen because all Pitzer parameters needed for the calculations are available. Pitzer parameters are not available for the vanadium salts used in AVRFBs, therefore the real OCVs in scenario \#2 were 
estimated using measurement data for setups with a cation exchange (catex) and an anion exchange (anex) membrane. We note briefly here that a model for volumetric properties of solutions used in AVRFBs based on variants of the Pitzer equations is available in the literature [48], but this model can of course not be used for the calculation of activity coefficients.

\section{Results and Discussion}

\section{$O C V$ of the $\mathrm{Fe} / \mathrm{Cd} \mathrm{RFB}$}

In scenario \#1, a Fe/Cd RFB with chloride salts only was studied, see Table 1 . Fig. 1 (a) shows the OCV curves for the ideal $\left(\gamma_{i}^{b *}=1\right)$ and real case $\left(\gamma_{i}^{b *}\right.$ calculated with the Pitzer model) as functions of the SOC.

\section{[Figure 1 about here.]}

As could be expected from the high concentrations of ionic species, a significant difference between the two curves corresponding to the ideal and the real case is found. The observed difference in the OCVs is solely caused by the influence of the activity coefficients, i.e. by the excess OCV $E_{\mathrm{ex}}$, which can be calculated using Eq. (3) and which is plotted in Fig. 1 (b). Therefore, activity coefficients should not be neglected in the Nernst equation.

When modeling the OCV of RFBs, it is often assumed that the ratio of activity coefficients and thus also $E_{\text {ex }}$ remains constant over the SOC, so that this contribution may simply be viewed as an additional additive contribution to the OCV, the so-called 'formal potential term' [33, 34, 35]. The present results show that this is not the case. By contrast, the excess OCV depends linearly on the SOC, with a coefficient of determination of about $R^{2}=0.99998$. In the supplementary material, a possible reason for the linear trend of the excess OCV vs. the SOC in the case of the Fe/Cd RFB is presented. There, the natural logarithm of all species' activity coefficients is shown as a function of the SOC. For most species, that property depends approximately linearly on the SOC. Consequently, when summing up these terms in the Nernst equation that linearity is preserved. However, we can only investigate this thoroughly for the Fe/Cd RFB, so that we cannot make any predictions whether this is only a peculiarity of the $\mathrm{Fe} / \mathrm{Cd} \mathrm{RFB}$ or a generic feature of RFBs. 
Moreover, $E_{\text {ex }}$ varies between $0.038 \mathrm{~V}(\mathrm{SOC} \rightarrow 0)$ and $-0.014 \mathrm{~V}(\mathrm{SOC} \rightarrow 1)$. Thus, it is in the same order of magnitude as the voltage losses during operation, which are discussed in more detail below.

\section{OCV of the AVRFB}

For the AVRFB, no Pitzer parameters are available. Thus, the calculation presented in the previous subsection cannot be simply repeated for the AVRFB. However, measurement data of the OCV are available [37], which can be used to estimate the excess OCV.

In the experiments conducted by Pavelka et al. [37], two AVRFB setups were investigated: one with a catex and one with an anex membrane. Both setups are considered here, see scenarios \#2a and \#2b in Table 1, using the reported overall compositions by Pavelka et al. [37.

Figs. 2(a) and 3(a) show the measured OCV data by Pavelka et al. [37] in comparison to the ideal OCV calculated with the present model. Additionally, the simulation results of the ideal OCV of Pavelka et al. are shown. Their calculations differ from the ones presented here in terms of the mass balances and the dissociation equilibrium of sulfuric acid, for which Pavelka et al. made additional assumptions. In the present work, the dissociation equilibrium is treated in a thermodynamically rigorous way. Furthermore, Figs. 2(b) and 3(b) show the calculated excess OCV (see Eq. (3)), which is the difference between the measured (real) OCV and the simulated (ideal) OCV illustrated in Figs. 2(a) and 3(a).

\section{[Figure 2 about here.]}

\section{(7)igure 3 about here.]}

As illustrated in Figs. 2 and 3, the simulated ideal OCVs for the setup with a catex membrane deviate significantly from the measured data, while in the case of the setup with an anex membrane, the differences are moderate, but still important. The maximum excess OCV is $0.28 \mathrm{~V}(\mathrm{SOC} \rightarrow 0)$ for the setup with the catex membrane and $0.08 \mathrm{~V}(\mathrm{SOC} \rightarrow 0)$ for the setup with the anex membrane, which is significantly higher than for the Fe/Cd RFB discussed in the previous subsection. Furthermore, the changes of the excess OCV over the SOC shown in Figs. 2(b) and 3(b) are larger than in the simulation results of the $\mathrm{Fe} / \mathrm{Cd} \mathrm{RFB}$. 
In this work, the dissociation equilibrium is treated in a thermodynamically rigorous way, but since the activity coefficients cannot be calculated due to a lack of Pitzer parameters, some uncertainties as to the reliability of the calculations remain and it is not possible to estimate the accuracy of the simulation results. It can only be noted that the developed model yields lower ideal OCVs for both simulated setups and thus larger excess OCVs than the model of Pavelka et al. [37]. Thus, the treatment of the dissociation equilibrium of sulfuric acid has a crucial influence on the OCV. Nevertheless, both sets of calculations, i.e. those of Pavelka et al. and those of the present work, indicate that the assumption of a constant excess OCV $E_{\text {ex }}[32,34]$ is not valid.

Evaluation of the regression lines obtained with the present model support the assumption that the dependence of $E_{\text {ex }}$ on the OCV could be described more accurately by a straight line, which validates the findings for the $\mathrm{Fe} / \mathrm{Cd} \mathrm{RFB}$ in the previous subsection.

Sensitivity of the $O C V$ on the composition of the electrolyte solution of the $\mathrm{Fe} / \mathrm{Cd}$ $R F B$

In this subsection, an optimization of the composition of the electrolyte solution towards high OCVs as described in scenario \#3 in Table 1 is discussed. In order to investigate the influence of activity coefficients on the results, the ideal and real OCV plots are compared. The contour plots shown in Fig. 4 summarize the results of the variation of the overall salt molarities and the variation of the overall $\mathrm{HCl}$ molarity. There, the OCV at an SOC of 0.5 is shown as an example, which is, however, representative for most of the entire SOC range (except for very high SOC).

[Figure 4 about here.]

For both the ideal and the real case, the model predicts that lower overall salt molarities lead to a higher OCV. In contrast, the variation of the $\mathrm{HCl}$ molarity shows different trends for the ideal and real cases: while the OCV rises with increasing $\mathrm{HCl}$ molarity in the ideal case, the real case predicts the opposite (except for very low acid molarities at high SOC). Hence, neglecting the activity coefficients is misleading when optimizing the OCV by varying the electrolyte composition: looking at the ideal case suggests lowering the acid concentration is beneficial, while in reality, the opposite is true. 
In Fig. 5, the results already shown in Fig. 4 are depicted in a different way to show the difference of the OCV between the typical operating point (cross) and other operating conditions: there, the same color scale is used for both the ideal and real cases. That color scale is set to zero for the typical operating point of the Fe/Cd RFB, see scenario \#1 in Table 1 .

[Figure 5 about here.]

Fig. 5 illustrates which overall compositions of the electrolyte solutions could enhance the OCV and shows the absolute difference to typical concentrations used in Fe/Cd RFBs [38]. The influence of the variation is assumed to be much smaller in the ideal case than it is in the real case. Hence, the full optimization potential of the RFB is underestimated if only the ideal part of the Nernst equation is taken into account.

\section{Influence of the excess $O C V$ on voltage losses in the $F e / C d R F B$}

RFBs during operation are considered in the following as described in scenario \#4 in Table 1, in contrast to the currentless state of equilibrium discussed above. Measurement data provided by Zeng et al. [38] are compared with calculated OCVs to estimate the occurring voltage losses. The measurement data of Zeng et al. [38 were carried out with a Fe/Cd RFB with chloride and sulfate salts. For this system, one set of Pitzer parameters, namely those of the $\mathrm{Cd}^{2+}-\mathrm{HSO}_{4}^{-}$interaction, are not available. In principle, this can lead to inaccuracies in modeling the activity coefficients. However, as the concentration of $\mathrm{Cl}^{-}$ions in the investigated RFB is typically 10 times larger than that of the $\mathrm{SO}_{4}^{2-}$ and $\mathrm{HSO}_{4}^{-}$ions, the impact of the missing parameters is presumably rather small. Furthermore, the binary parameters of all other combinations of anions and cations of the described electrolyte solution are available.

Zeng et al. [38] reported measured cell voltage data during charging of a $\mathrm{Fe} / \mathrm{Cd} \mathrm{RFB}$ as a function of time for four different current densities. Furthermore, the electrolyte utilization at the cut-off voltage $(1.35 \mathrm{~V})$ is given for each case. Explanations for the relatively low electrolyte utilization are already provided by Zeng et al. 38] and are not discussed here. Based on the reported data, the cell voltage curves as a function of the SOC (see Eq. (25)) were derived. In terms of the SOC definition used in the present work, the charging experiments by Zeng et al. start at $\mathrm{SOC}=0$. The $\mathrm{SOC}$ at the end of the experiment can be determined from 
the electrolyte utilization provided by Zeng et al. [38], in the following we discuss only the current densities $40 \mathrm{~mA} \mathrm{~cm}^{-2}$ and $160 \mathrm{~mA} \mathrm{~cm}^{-2}$.

The data of the charge process provided by Zeng et al. 38] show that the measured cell voltage rises with increasing current density, which is due to currentdependent voltage losses during charging of the RFB. As outlined in the introduction, the voltage losses are calculated as

$$
E_{\text {losses, real }}=E_{\text {cell }}-E_{\text {cell, real }}^{\text {rev }}
$$

where $E_{\text {losses, real }}$ is the true sum of all voltage losses, i.e. considering the activity coefficients when calculating the OCV. Hence, inaccuracies in the calculation of the OCV, such as the neglect of activity coefficients, lead to errors in the calculation of voltage losses. To distinguish the two approaches, the term $E_{\text {losses, ideal }}$ is introduced in the following as

$$
E_{\text {losses, ideal }}=E_{\text {cell }}-E_{\text {cell, ideal }}^{\text {rev }}
$$

to indicate the losses that one would expect when calculating the OCV without activity coefficients. Combining Eqs. (4), (35) and (36) yields

$$
E_{\text {losses, ideal }}=E_{\text {losses, real }}+E_{\text {ex }}
$$

Eq. (37) clearly shows that the neglect of the excess OCV leads to erroneous estimations of the voltage losses.

Figs. 6(a) and 7(a) illustrate the comparison of the simulated ideal and real OCV with the measurement data of Zeng et al. 38] for the two applied current densities. Furthermore, Figs. 6(b) and 7(b) show the ideal and real voltage losses calculated from the data in Figs. 6(a) and 7(a), as well as the excess OCV.

[Figure 6 about here.]

[Figure 7 about here.]

The excess OCV describes the equilibrium state and is therefore only a function of the SOC, but does not depend on the applied current density. At an applied current density of $40 \mathrm{~mA} \mathrm{~cm} \mathrm{~cm}^{-2}$, the calculated voltage losses are small and in the order of magnitude of the excess OCV. Hence, when calculating voltage losses with respect to $E_{\text {cell, ideal }}^{\text {rev }}$ an appreciable error can be made: the voltage losses can be 
under- or overestimated to a large extent. Higher applied current densities lead to increasing voltage losses caused by overpotentials and ohmic losses, so that the relative difference between ideal and real voltage losses decreases. Therefore, the thermodynamically rigorous calculation of the OCV is especially important when studying voltage losses in RFB setups at low current densities.

In the literature, the experimental data of ideal voltage losses of lab-scale RFB setups are often used to adjust model parameters, e.g. the kinetic parameters in the Butler-Volmer equations for the calculation of activation overpotentials [17, 22, 23, 28, 49, 50. However, the present results indicate that the ideal voltage losses under- or overestimate the real voltage losses. As a result, the obtained fit parameters have to effectively capture phenomena that should rather be included in the description of the equilibrium state. Both the voltage losses and the excess OCV depend on the SOC, but not necessarily in the same functional form. Even if they did, that functional form would not be known. The/excess OCV and the voltage losses (see Eq. (1)) should therefore be treated independently. Hence, a precise calculation of the OCV can help to evaluate the required fit parameters more accurately for a wide range of operating regimes in order to improve existing models.

For the AVRFB, the calculations presented in this subsection cannot be simply repeated due to a lack of necessary Pitzer parameters or data from which these parameters could be obtained. Instead, we implemented the zero-dimensional model by Sharma et al. [17] to get an estimate of the magnitude of the different types of voltages losses. The predicted types of voltage losses (activation overpotentials and ohmic losses of the current collector, electrolyte, and membrane) are smaller or of the same magnitude as the estimated excess OCV of a typical AVRFB examined above. This supports the hypothesis that activity coefficients are essential for an accurate modeling of RFBs and should not be neglected.

\section{Conclusions}

In this work, the hypothesis was investigated that considering activity coefficients in electrolyte solutions is essential for the modeling of RFBs. By simulating a Fe/Cd RFB and using measurement data from an AVRFB, it could be demonstrated that the excess $\mathrm{OCV}$ is substantial and should not be neglected. Moreover, in contrast to a common assumption in the literature, the excess OCV is not a constant, but rather varies with the SOC. Our results for both RFBs show a linear relationship between 
the excess OCV and the SOC, however, this linear dependence is not necessarily a unique feature for all RFBs. Nonetheless, these results show that the introduction of a so-called 'formal potential term' is thermodynamically invalid. Furthermore, using measurement data from a Fe/Cd RFB during operation, it was shown that voltage losses are in the same order of magnitude as the excess OCV, so that their estimation depends strongly on the way the OCV is calculated. With this new approach, this work proves that activity coefficients have a significant influence on the modeling of RFBs that should not be neglected.

Additionally, the developed model provides the framework for conducting sensitivity studies. This was demonstrated by investigating the sensitivity of the OCV of a Fe/Cd RFB on the composition of the electrolyte solution. The observed dependencies of the $\mathrm{OCV}$ on the overall molarities of the electrolyte solutions would be misinterpreted if activity coefficients were neglected. Potentially, the obtained results can be used to optimize the composition of the electrolyte solution of a $\mathrm{Fe} / \mathrm{Cd} \mathrm{RFB}$. In the present work, the solubilities of the électrolytes and the stability of the RFB electrolyte solution was not considered. Therefore, in future applications of the model, e.g. for multicriteria optimization of the composition of the electrolyte solution, a calculation of the electrolyte solubilities should be added.

The results of the present work indicate that in future work, activity data of the electrolyte solutions in the AVFRB should be measured, and a thermodynamic model, e.g. the Pitzer model, should be fitted to these data. In literature models, the required parameters for voltage losses are usually obtained by a fit to data of lab-scale RFB setups, a procedure which is prone to errors due to an inaccurate OCV calculation. Therefore, implementing a thermodynamically accurate model to describe the electrolyte solutions used in RFBs has the potential to significantly improve the simulations of the OCV, the cell voltage, and voltage losses, thus improving the understanding of RFBs in general and allowing for a more robust cell design.

\section{List of Symbols}


Greek

$\gamma_{i}^{b *}$

$\eta$

$\mu_{i}$

$\mu_{i}^{0, b}$

$\mu_{i}^{\mathrm{elc}}$

$\nu_{i}$

$\Phi$

Thermodynamically rigorous description of the $O C V$ of $R F B s$

$b_{i} \quad$ molality of species $i, \mathrm{~mol} \mathrm{~kg}^{-1}$

$E_{\text {cell }}$

$E_{\text {cell }}^{0}$

$E_{\text {cell }}^{\text {rev }}$

$E_{\text {losses }}$

$E_{\text {ex }}$

F

$K_{\mathrm{a}}$

$m_{i}$

$M_{i}$

$n_{i}$

$N$

$p$

$R$

$R^{2}$

$T$

$z_{i}$

cell voltage, $\mathrm{V}$

standard electrode potential, $\mathrm{V}$

open circuit voltage, $\mathrm{V}$

voltage losses, $\mathrm{V}$

excess open circuit voltage, $\mathrm{V}$

Faraday's constant, 96487 A s mol ${ }^{-1}$

dissociation constant, -

mass of species $i, \mathrm{~kg}$

molar mass of species $i, \mathrm{~kg} \mathrm{~mol}{ }^{-1}$

number of moles of species $i$, mol

number of components, -

pressure, $\mathrm{Pa}$

universal gas constant, $8.314 \mathrm{~J} \mathrm{~mol}^{-1} \mathrm{~K}^{-1}$ )

coefficient of determination, -

temperature, $\mathrm{K}$

charge number of species $i,-$

molality-based activity coefficient of species $i$, -

overpotential, $\mathrm{V}$

chemical potential of species $i, \mathrm{~J} \mathrm{~mol}^{-1}$

molality-based standard chemical potential of species $i, \mathrm{~J} \mathrm{~mol}^{-1}$

electrochemical potential of species $i, \mathrm{~J} \mathrm{~mol}^{-1}$

stoichiometric coefficient of species $i,-$

electrostatic potential, $\mathrm{V}$

\section{Subscripts and Superscripts}

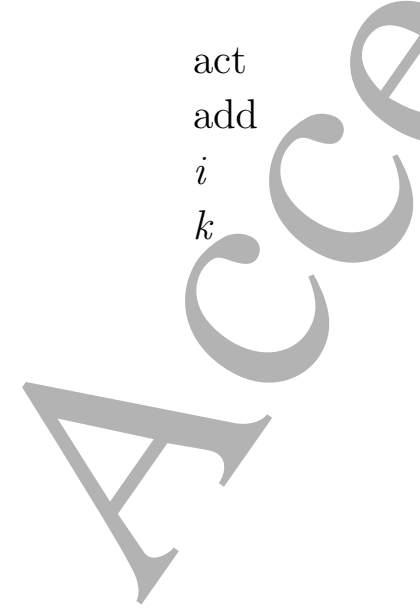

activation

additional

species $i$

functional layer $k$ 
Thermodynamically rigorous description of the OCV of RFBs

$\mathrm{m}, \mathrm{m}$ metal phase

$\mathrm{Me} \quad$ metal

neg negative electrode

ohm ohmic loss

ox oxidized

pos positive electrode

red reduced

rev reversible

tot total

W water

\section{Appendix: Derivation of the OCV of a Fe/Cd RFB}

In the following, the Nernst equation for describing the $\mathrm{OCV}$ of a Fe/Cd RFB is derived. The approach is similar to that of Pavelka et al. [37] and Muñoz et al. [32] for the AVRFB. Chemical equilibrium for both half-cell reactions (IV) and (V) (see Model development section) is given by the equality of the electrochemical potentials:

$$
\begin{gathered}
2 \mu_{\mathrm{Fe}^{3+}}^{\text {elc,pos }}+2 \mu_{\mathrm{e}^{-}}^{\text {elc,m }}=2 \mu_{\mathrm{Fe}^{2+}}^{\text {elc,pos }} \\
\mu_{\mathrm{Cd}^{2+}}^{\text {elc,neg }}+2 \mu_{\mathrm{e}^{-}}^{\text {elc,m' }}=\mu_{\mathrm{Cd}}^{\text {elc,neg }}
\end{gathered}
$$

Here, $\mathrm{m}$ and $\mathrm{m}$ ' represent the phase of the wires connecting the voltmeter and the terminals of the battery [32. By/inserting the definition of the electrochemical potential (see supplementary material) into (A.1) and (A.2), the following equations are obtained:

$$
\begin{aligned}
& F\left(\Phi^{\mathrm{m}}-\Phi^{\mathrm{pos}}\right)=\mu_{\mathrm{Fe}^{3+}}^{\mathrm{pos}}+\mu_{\mathrm{e}^{-}}^{\mathrm{m}}-\mu_{\mathrm{Fe}^{2+}}^{\mathrm{pos}} \\
& F\left(\Phi^{\mathrm{m}^{\prime}}-\Phi^{\mathrm{neg}}\right)=\frac{1}{2} \mu_{\mathrm{Cd}^{2+}}^{\mathrm{neg}}+\mu_{\mathrm{e}^{-}}^{\mathrm{m}}-\frac{1}{2} \mu_{\mathrm{Cd}}^{\mathrm{neg}}
\end{aligned}
$$

Since a proton-permeable catex membrane is used, the electrochemical potential of protons has to be the same in both half-cells [37], resulting in

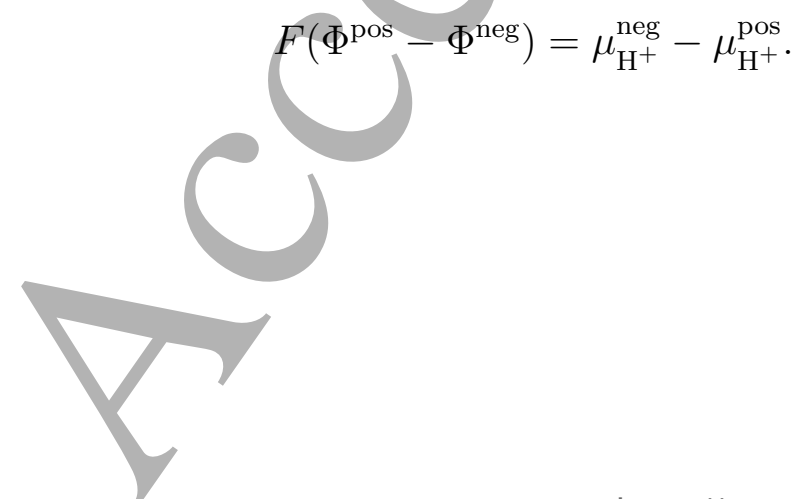


Thermodynamically rigorous description of the OCV of RFBs

Combining Eqs. A.3 - A.5 leads to

$$
\begin{aligned}
F\left(\Phi^{\mathrm{m}}-\Phi^{\mathrm{m}}\right) & =F E_{\mathrm{cell}}^{\mathrm{rev}} \\
& =\mu_{\mathrm{Fe}^{3+}}^{\mathrm{pos}}-\mu_{\mathrm{Fe}^{2+}}^{\mathrm{pos}}-\frac{1}{2} \mu_{\mathrm{Cd}^{2+}}^{\mathrm{neg}}+\frac{1}{2} \mu_{\mathrm{Cd}}^{\mathrm{neg}}+\mu_{\mathrm{H}^{+}}^{\mathrm{neg}}-\mu_{\mathrm{H}^{+}}^{\mathrm{pos}}
\end{aligned}
$$

An appropriate normalization (see supplementary material) of the electrochemical potentials in Eq. A.6. yields

$$
\begin{aligned}
E_{\mathrm{cell}}^{\mathrm{rev}} & =\frac{1}{F}\left(\mu_{\mathrm{Fe}^{3+}}^{0, b, \text { pos }}-\mu_{\mathrm{Fe}^{2+}}^{0, b, \text { pos }}-\frac{1}{2} \mu_{\mathrm{Cd}^{2+}}^{0, b, \text { neg }}+\frac{1}{2} \mu_{\mathrm{Cd}}^{0, b, \text { neg }}\right) \\
& +\frac{R T}{F} \ln \left(\frac{a_{\mathrm{Fe}^{3+}}^{\mathrm{pos}} a_{\mathrm{H}^{+}}^{\mathrm{neg}}\left(a_{\mathrm{Cd}}^{\mathrm{neg}}\right)^{1 / 2}}{a_{\mathrm{Fe}^{2+}}^{\mathrm{pos}} a_{\mathrm{H}^{+}}^{\mathrm{pos}}\left(a_{\mathrm{Cd}^{2+}}^{\mathrm{neg}}\right)^{1 / 2}}\right) .
\end{aligned}
$$

Furthermore, the standard electrode potentials of both half-cells [38] can be expressed as

$$
\begin{aligned}
& E_{\mathrm{pos}}^{0}=\frac{1}{F}\left(\mu_{\mathrm{Fe}^{3+}}^{0, b}-\mu_{\mathrm{Fe}^{2+}}^{0, b}\right)=0.77 \mathrm{~V} \\
& E_{\mathrm{neg}}^{0}=\frac{1}{2 F}\left(\mu_{\mathrm{Cd}^{2+}}^{0, b}-\mu_{\mathrm{Cd}}^{0, b}\right)=-0.40 \mathrm{~V},
\end{aligned}
$$

leading to the standard electrode potential of the Fe/Cd RFB

$$
E_{\mathrm{cell}}^{0}=E_{\mathrm{pos}}^{0}-E_{\mathrm{neg}}^{0}=\frac{1}{F}\left(\mu_{\mathrm{Fe}^{3+}}^{0, b}-\mu_{\mathrm{Fe}^{2+}}^{0, b}-\frac{1}{2} \mu_{\mathrm{Cd}^{2+}}^{0, b}+\frac{1}{2} \mu_{\mathrm{Cd}}^{0, b}\right)=1.17 \mathrm{~V}
$$

Finally, inserting Eqs. A.8 - A.10 into A.7 gives the result

$$
E_{\text {cell }}^{\mathrm{rev}}=E_{\mathrm{cell}}^{0}+\frac{R T}{2 F} \ln \left(\frac{\left(a_{\mathrm{Fe}}^{\mathrm{pos}}\right)^{2}\left(a_{\mathrm{H}^{+}}^{\mathrm{neg}}\right)^{2} a_{\mathrm{Cd}}^{\mathrm{neg}}}{\left(a_{\mathrm{Fe}^{2+}}^{\mathrm{pos}}\right)^{2}\left(a_{\mathrm{H}^{+}}^{\mathrm{pos}}\right)^{2} a_{\mathrm{Cd}^{2+}}^{\mathrm{ne}}}\right) .
$$

Eq. A.11 is the thermodynamically rigorous Nernst equation for the Fe/Cd RFB. 
Thermodynamically rigorous description of the $O C V$ of $R F B s$

\section{References}

[1] J. Conti, P. Holtberg, J. Diefenderfer, A. LaRose, J. T. Turnure, L. Westfall: International energy outlook 2016 with projections to 2040, Technical Report, USDOE Energy Information Administration (EIA), Washington, DC (United States) (2016).

[2] P. Alotto, M. Guarnieri, F. Moro: Redox flow batteries for the storage of renewable energy: A review, Renewable and Sustainable Energy Reviews 29 (2014) 325-335.

[3] M. K. Ravikumar, S. Rathod, N. Jaiswal, S. Patil, A. Shukla: The renaissance in redox flow batteries, Journal of Solid State Electrochemistry 21 (2017) 2467-2488.

[4] A. Z. Weber, M. M. Mench, J. P. Meyers, P. N. Ross, J. T. Gostick, Q. Liu: Redox flow batteries: a review, Journal of Applied Electrochemistry 41 (2011) 1137.

[5] E. Sum, M. Skyllas-Kazacos: A study of the V(II)/V(III) redox couple for redox flow cell applications, Journal of Power Sources 15 (1985) 179-190.

[6] E. Sum, M. Rychcik, M. Skyllas-Kazacos: Investigation of the $\mathrm{V}(\mathrm{V}) / \mathrm{V}(\mathrm{IV})$ system for use in the positive half-cell of a redox battery, Journal of Power Sources 16 (1985) 85-95.

[7] G. Kear, A. A. Shah, F. C. Walsh: Development of the all-vanadium redox flow battery for energy storage: a review of technological, financial and policy aspects, International Journal of Energy Research 36 (2012) 1105-1120.

[8] C. Minke, T. Turek: Materials, system designs and modelling approaches in techno-economic assessment of all-vanadium redox flow batteries - A review, Journal of Power Sources $\mathbf{3 7 6}$ (2018) 66-81.

[9] K. J. Kim, M.-S. Park, Y.-J. Kim, J. H. Kim, S. X, Dou, M. Skyllas-Kazacos: A technology review of electrodes and reaction mechanisms in vanadium redox flow batteries, Journal of Materials Chemistry A 3 (2015) 16913-16933.

[10] C. Lenihan, D. Oboroceanu, N. Quill, D. Ní Eidhin, A. Bourke, R. P. Lynch, D. N. Buckley: Water Affinity of Vanadium Electrolytes, ECS Transactions 85 (2018) 175-189.

[11] Y. K. Zeng, T. S. Zhao, L. An, X. L. Zhou, L. Wei: A comparative study of all-vanadium and iron-chromium redox flow batteries for large-scale energy storage, Journal of Power Sources 300 (2015) 438-443.

[12] W. Wang, Q. Luo, B. Li, X. Wei, L. Li, Z. Yang: Recent Progress in Redox Flow Battery Research and Development, Advanced Functional Materials 23 (2013) 970-986.

[13] R. Ye, D. Henkensmeier, S. J. Yoon, Z. Huang, D. K. Kim, Z. Chang, S. Kim, R. Chen: Redox Flow Batteriès fôr Energy Storage: A Technology Review, Journal of Electrochemical Energy Conversion and Storage 15 (2018) 010801.

[14] F. Pan, Q. Wang: Redox Species of Redox Flow Batteries: A Review, Molecules 20 (2015) 20499-20517.

[15] Y. Shi, C. Eze, B. Xiong, W. He, H. Zhang, T. M. Lim, A. Ukil, J. Zhao: Recent development of membrane for vanadium redox flow battery applications: A review, Applied Energy 238 (2019) 202-224.

[16] A. A. Shah, R. Tangirala, R. Singh, R. G. A. Wills, F. C. Walsh: A Dynamic Unit Cell Model for the All-Vanadium Flow Battery, Journal of The Electrochemical Society 158 (2011) A671-A677. 
[17] A. K. Sharma, C. Y. Ling, E. Birgersson, M. Vynnycky, M. Han: Verified reduction of dimensionality for an all-vanadium redox flow battery model, Journal of Power Sources 279 (2015) 345-350.

[18] M. Pugach, M. Kondratenko, S. Briola, A. Bischi: Zero dimensional dynamic model of vanadium redox flow battery cell incorporating all modes of vanadium ions crossover, Applied Energy 226 (2018) 560-569.

[19] M. Vynnycky: Analysis of a model for the operation of a vanadium redox battery, Energy 36 (2011) 2242-2256.

[20] C. L. Chen, H. K. Yeoh, M. H. Chakrabarti: An enhancement to Vynnycky's model for the all-vanadium redox flow battery, Electrochimica Acta 120 (2014) 167-179.

[21] D. You, H. Zhang, J. Chen: A simple model for the vanadium redox battery, Electrochimica Acta 54 (2009) 6827-6836.

[22] K. W. Knehr, E. Agar, C. R. Dennison, A. R. Kalidindi, E. C. Kumbur; A Transient Vanadium Flow Battery Model Incorporating Vanadium Crossover and Water Transport through the Membrane, Journal of The Electrochemical Society 159 (2012) A1446-A1459.

[23] A. K. Sharma, M. Vynnycky, C. Y. Ling, E. Birgersson, M. Han: The quasi-steady state of all-vanadium redox flow batteries: A scale analysis, Electrochimica Acta 147 (2014) 657-662.

[24] K. Oh, H. Yoo, J. Ko, S. Won, H. Ju: Three-dimensional, transient, nonisothermal model of all-vanadium redox flow batteries, Energy 81 (2015) 3-14.

[25] Q. Wang, Z. Qu, Z. Jiang, W. Yang: Numerical study on vanadium redox flow battery performance with non-uniformly compressed electrode and serpentine flow field, Applied Energy 220 (2018) 106-116.

[26] C. H. Hamann, W. Vielstich: Elektrochemie, Wiley-VCH, Weinheim, 1998, 3rd edition.

[27] G. Job, R. Rüffler (Eds.): Physikalische Chemie: Eine Einführung nach neuem Konzept mit zahlreichen Experimenten, Vieweg+Teubner Verlag / Springer Fachmedien Wiesbaden GmbH Wiesbaden, Wiesbaden, 2011, 1st édition.

[28] H. Al-Fetlawi, A. A. Shah, F. C. Walsh? Modelling the effects of oxygen evolution in the all-vanadium redox flow battery, Electrochimica Acta 55 (2010) 3192-3205.

[29] D. Chen, S. Wang, M. Xiao, Y. Meng: Preparation and properties of sulfonated poly (fluorenyl ether ketone) membrane for vanadium redox flow battery application, Journal of Power sources 195 (2010) 2089-2095.

[30] K. W. Knehr, E. C. Kumbur: Open circuit voltage of vanadium redox flow batteries: Discrepancy between models and experiments, Electrochemistry Communications 13 (2011) $342-345$.

[31] Y. A. Gandomi, D. Aaron, T. Zawodzinski, M. Mench: In situ potential distribution measurement and validated model for all-vanadium redox flow battery, Journal of The Electrochemical Society 163 (2016) A5188-A5201.

[32] C. A. P. Muñoz, H. H. Dewage, V. Yufit, N. P. Brandon: A Unit Cell Model of a Regenerative Hydrogen-Vanadium Fuel Cell, Journal of The Electrochemical Society 164 (2017) F1717F1732.

[33] S. Corcuera, M. Skyllas-Kazacos: State-of-charge monitoring and electrolyte rebalancing methods for the vanadium redox flow battery, European Chemical Bulletin 1 (2012) 511-519.

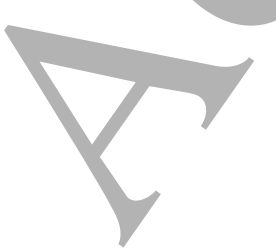


Thermodynamically rigorous description of the $O C V$ of $R F B s$

[34] M. Skyllas-Kazacos, L. Cao, M. Kazacos, N. Kausar, A. Mousa: Vanadium Electrolyte Studies for the Vanadium Redox Battery-A Review, ChemSusChem 9 (2016) 1521-1543.

[35] S. K. Murthy, A. K. Sharma, C. Choo, E. Birgersson: Analysis of Concentration Overpotential in an All-Vanadium Redox Flow Battery, Journal of The Electrochemical Society 165 (2018) A1746-A1752.

[36] M. Kohns, G. Lazarou, E. Forte, F. A. Perdomo, S. Kournopoulos, G. Jacksson, C. Adjiman, A. Galindo: Predictive models for the phase behaviour and solution properties of weak electrolytes: nitric, sulfuric and carbonic acid., Physical Chemistry Chèmical Physics, accepted .

[37] M. Pavelka, F. Wandschneider, P. Mazur: Thermodynamic derivation of open circuit voltage in vanadium redox flow batteries, Journal of Power Sources 293 (2015) 400-408.

[38] Y. K. Zeng, T. S. Zhao, X. L. Zhou, L. Wei, H. R. Jiang: A low-cost iron-cadmium redox flow battery for large-scale energy storage, Journal of Power Sources 330 (2016) 55-60.

[39] S. L. Clegg, J. A. Rard, K. S. Pitzer: Thermodynamic properties of $0-6 \mathrm{~mol} \mathrm{~kg}^{-1}$ aqueous sulfuric acid from 273.15 to 328.15 K, J. Chem. Soc., Faraday Trans. 90 (1994) 1875-1894.

[40] S. A. Bea, J. Carrera, C. Ayora, F. Batlle: Modeling of concentrated aqueous solutions: Efficient implementation of Pitzer equations in geochemical and reactive transport models, Computers $\mathscr{E}$ Geosciences 36 (2010) 526-538.

[41] K. S. Pitzer: Thermodynamics of electrolytes. I. Theoretical basis and general equations, Journal of Physical Chemistry 77 (1973) 268-277.

[42] K. S. Pitzer, G. Mayorga: Thermodynamies of electrolytes. II. Activity and osmotic coefficients for strong electrolytes with one or both ions univalent, The Journal of Physical Chemistry 77 (1973) 2300-2308.

[43] K. S. Pitzer, J. J. Kim: Thermodynamics of electrolytes. IV. Activity and osmotic coefficients for mixed electrolytes, Journal of the American Chemical Society 96 (1974) 5701-5707.

[44] K. S. Pitzer, G. Mayorga: Thermodynamics of electrolytes. III. Activity and osmotic coefficients for 2-2 electrolytes, Journal of Solution Chemistry 3 (1974) 539-546.

[45] K. S. Pitzer: Thermodynamics of electrolytes. V. Effects of higher-order electrostatic terms, Journal of Solution Chemistry 4 (1975) 249-265.

[46] C. E. Harvie, J. H. Weare: The prediction of mineral solubilities in natural waters: the Na$\mathrm{K}-\mathrm{Mg}$-Ca-Cl- $-\mathrm{SO}_{4}-\mathrm{H}_{2} \mathrm{O}$ system from zero to high concentration at $25{ }^{\circ} \mathrm{C}$, Geochimica et Cosmochimica Acta 44 (1980) 981-997.

[47] MATLAB R2018a, The Mathworks, Inc., Natick, Massachusetts, US.

[48] W.-G. Xu, Y. Qin, F. Gao, J.-G. Liu, C.-W. Yan, J.-Z. Yang: Determination of volume properties of aqueous vanadyl sulfate at 283.15 to $323.15 \mathrm{~K}$, Industrial and Engineering Chemistry Research 53 (2014) 7217-7223.

[49] A. A. Shah, M. J. Watt-Smith, F. C. Walsh: A dynamic performance model for redox-flow batteries involving soluble species, Electrochimica Acta 53 (2008) 8087-8100.

[50] H. Al-Fetlawi, A. A. Shah, F. C. Walsh: Non-isothermal modelling of the all-vanadium redox flow battery, Electrochimica Acta 55 (2009) 78-89.

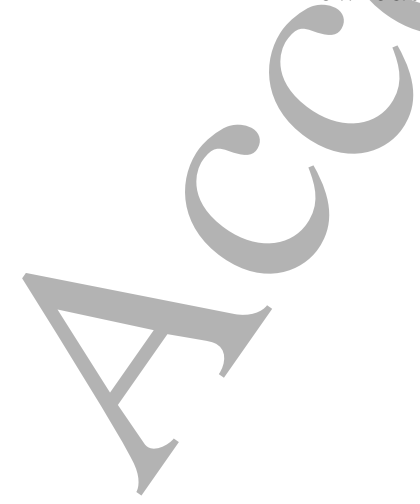

https://mc04.manuscriptcentral.com/jes-ecs 


\section{FIGURES}

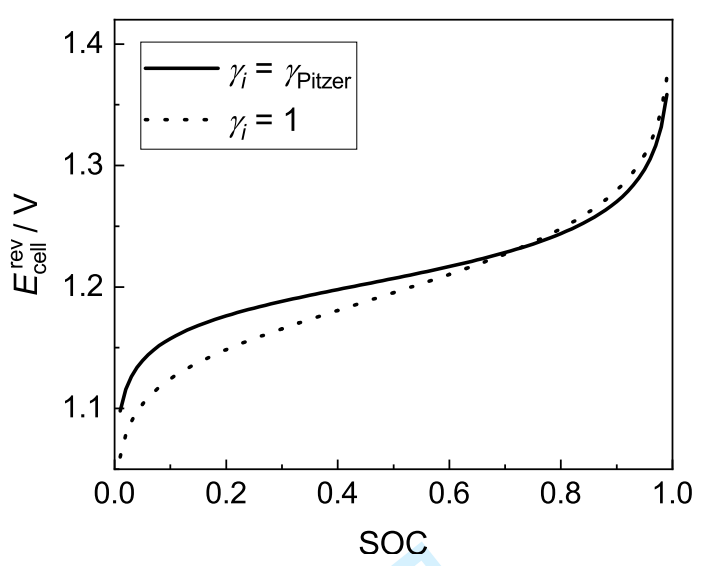

(a)

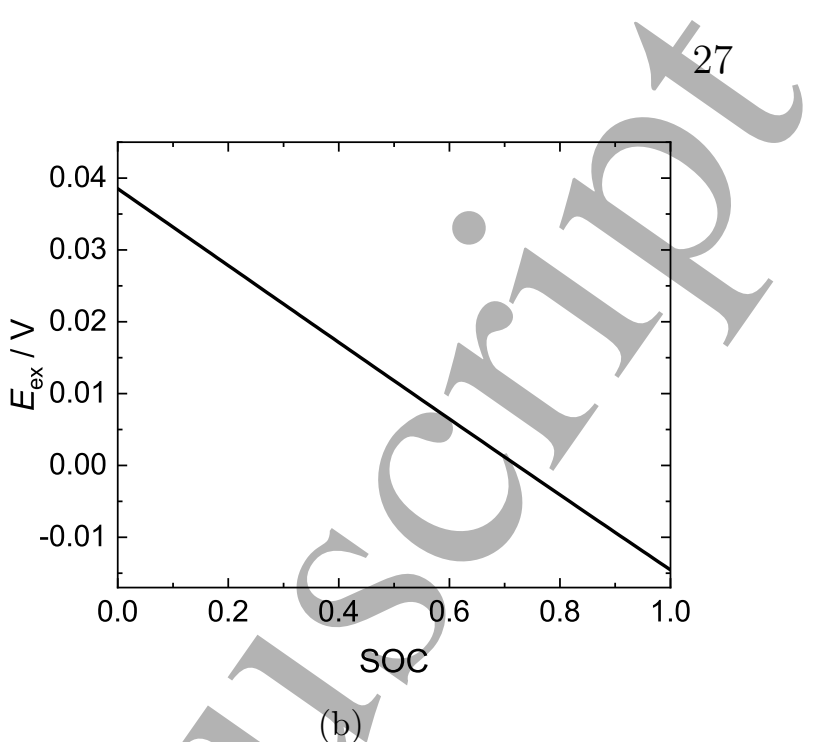

Figure 1. (a) OCV of the $\mathrm{Fe} / \mathrm{Cd} \mathrm{RFB}$ with chloride salts only as a function of the SOC calculated with the present model. Dotted line: ideal case (neglect of activity coefficients), solid line: real case (activity coefficients from Pitzer model). (b) Excess OCV $\left(E_{\text {ex }}\right)$ of the $\mathrm{Fe} / \mathrm{Cd} \mathrm{RFB}$ with chloride salts only according to Eq. (3), as a function of the SOC. 


\section{FIGURES}

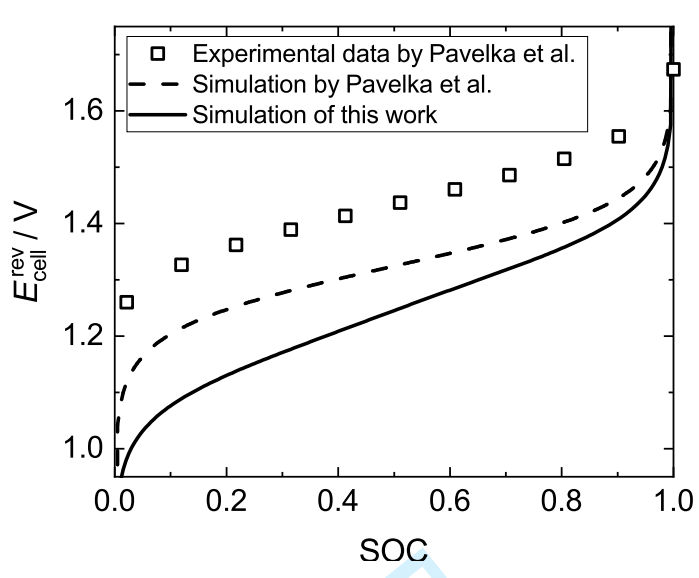

(a)

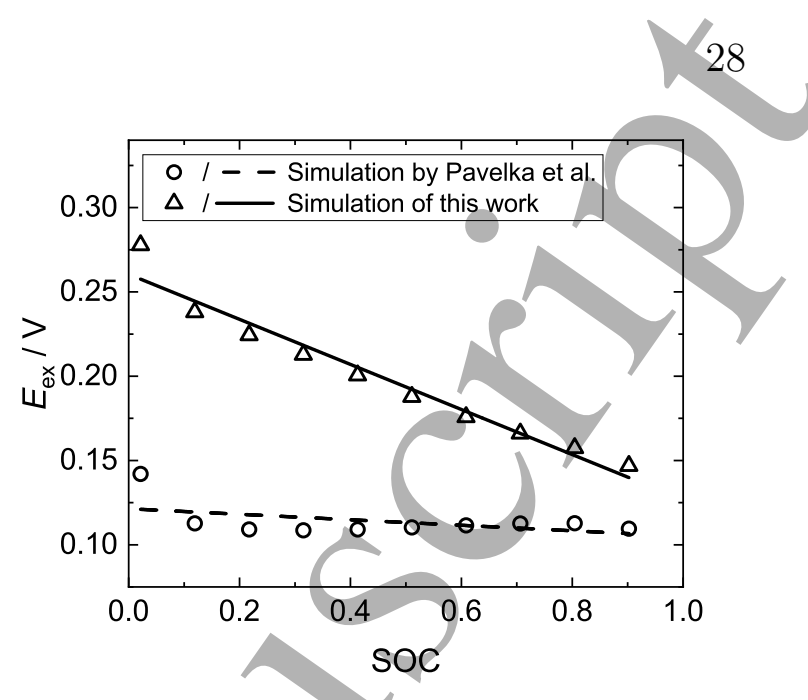

(b)

Figure 2. AVRFB with a catex membrane. (a) Comparison of the simulated ideal OCV according to Pavelka et al. 37. (dashed line), the simulated ideal OCV from this work with explicit treatment of the dissociation of sulfuric acid (solid line) and the experimental real OCV data from Pavelka et al. (open symbols). The activity coefficients were neglected in the simulations. (b) Difference between the experimental data from Pavelka et al. [37] and the simulated OCV according to Pavelka et al. (circles) or the simulated OCV with explicit treatment of the dissociation of sulfuric acid (triangles), as presented in (a). In addition, linear fits of the data are shown (dashed line: $R^{2}=0.23217$; solid line: $R^{2}=0.95588$ ). 


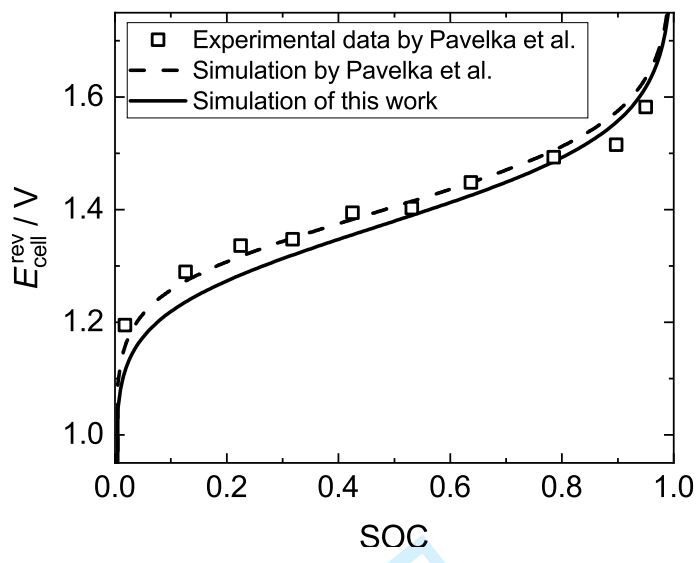

(a)

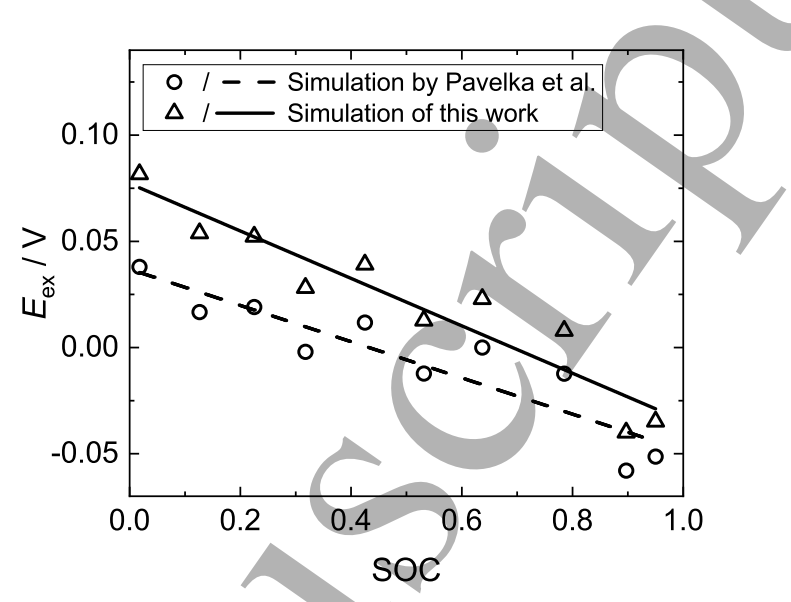

(b)

Figure 3. AVRFB with an anex membrane. (a) Comparison of the simulated ideal OCV according to Pavelka et al. 37] (dashed line), the simulated ideal OCV from this work with explicit treatment of the dissociation of sulfuric acid (solid/line) and the experimental real OCV data from Pavelka et al. (open symbols). The activity coefficients were neglected in the simulations. (b) Difference between the experimental data from Pavelka et al. 37] and the simulated OCV according to Pavelka et al. (circles) or the simulated OCV with explicit treatment of the dissociation of sulfuric acid (triangles), as presented in (a). In addition, linear fits of the data are shown (dashed line: $R^{2}=0.83265$; solid line: $R^{2}=0.89589$ ). 


\section{FIGURES}

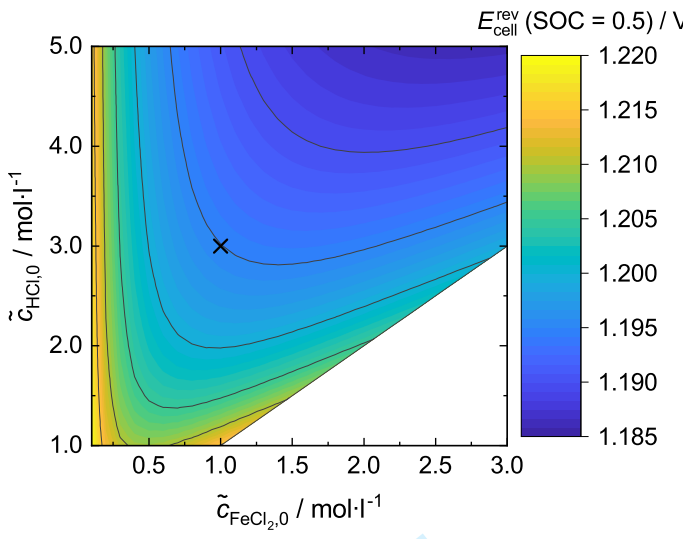

(a)

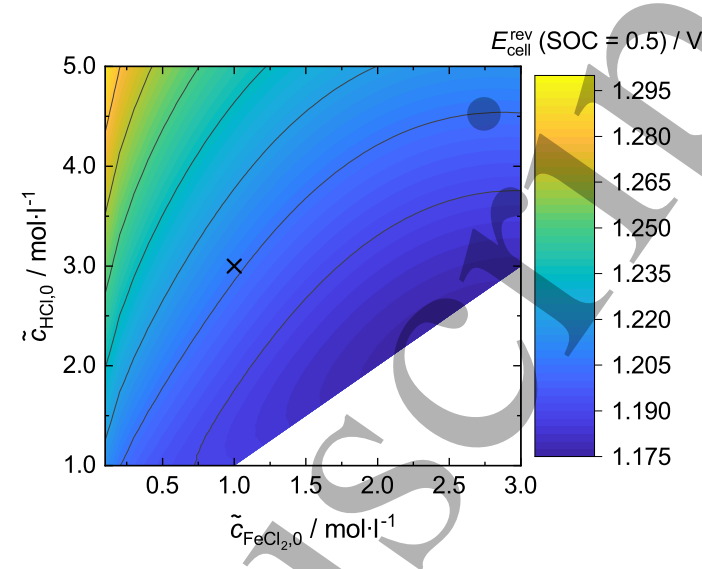

(b)

Figure 4. Simulated $\mathrm{OCV}$ at an $\mathrm{SOC}$ of 0.5 with variation of the overall molarities of $\mathrm{FeCl}_{2}$ between 0.1 and $3.0 \mathrm{~mol} \mathrm{l}^{-1}$ and of $\mathrm{HCl}$ between 1.0 and $5.0 / \mathrm{mol} \mathrm{l}^{-1}$. The overall $\mathrm{CdCl}_{2}$ molarity is always half that of $\mathrm{FeCl}_{2}$. The cross indicates the typical overall composition of the electrolyte solution of the Fe/Cd RFB with chloride salts only (see scenario \#1 in Table 1 38). No simulation data can be generated for the white area, since the quantity of protons is not sufficient for charge equalization over the entire SOC. (a) Ideal case (neglect of activity coefficients). (b) Real case (activity coefficients from Pitzer model). 


\section{FIGURES}

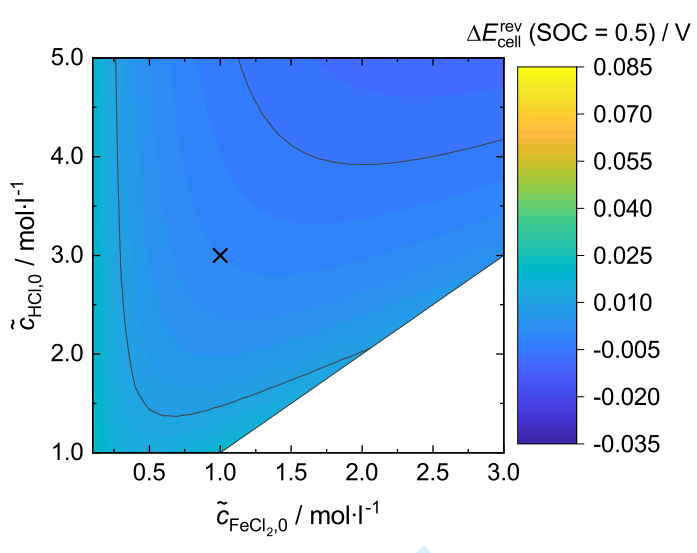

(a)

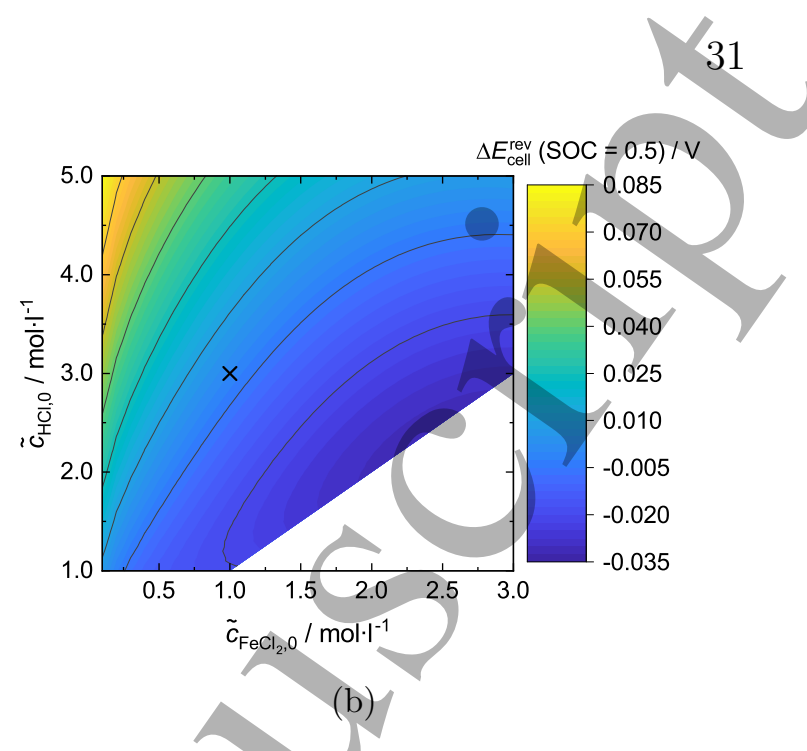

Figure 5. Deviations of the OCV at an SOC of 0.5 from the typical operating point (cross; see scenario \#1 in Table 1 38] ) of the Fe/Cd RFB with chloride salts only. Variation of the overall molarities of $\mathrm{FeCl}_{2}$ between 0.1 and $3.0 \mathrm{~mol} \mathrm{l}^{-1}$ and of $\mathrm{HCl}$ between 1.0 and $5.0 \mathrm{~mol} \mathrm{l}^{-1}$. The overall $\mathrm{CdCl}_{2}$ molarity is always half that of $\mathrm{FeCl}_{2}$. No simulation data can be generated for the white area, since the quantity of protons is not sufficient for charge equalization over the entire SOC. (a) Ideal case (neglect of activity coefficients). (b) Real case (activity coefficients from Pitzer model). 


\section{FIGURES}

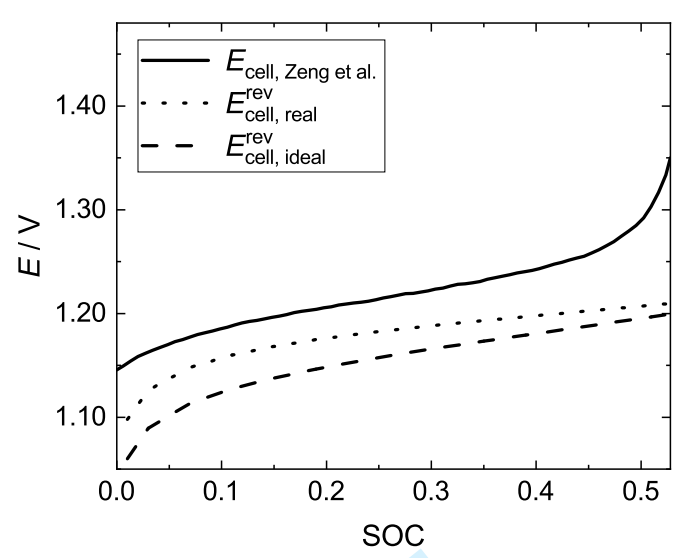

(a)

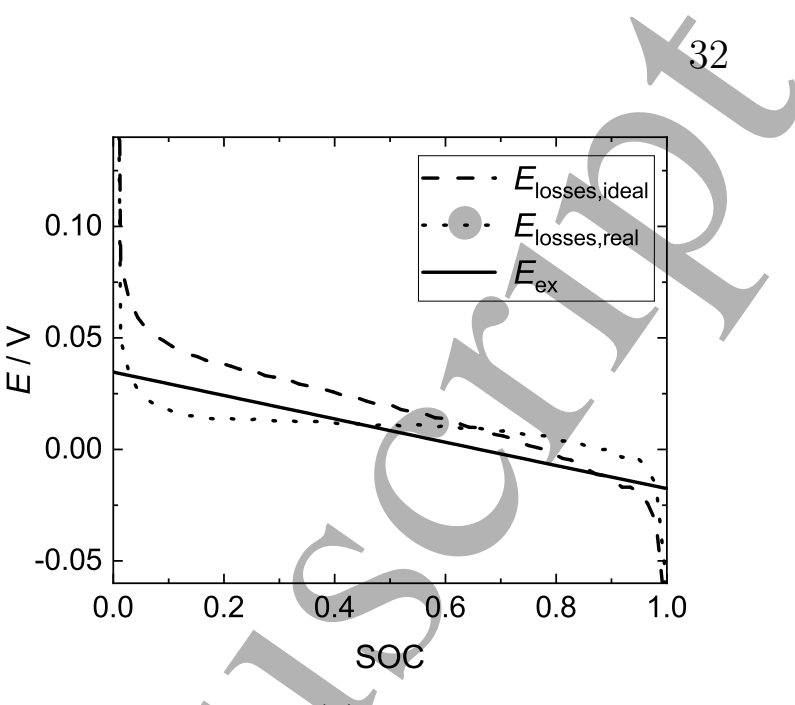

Figure 6. Applied current density: $40 \mathrm{~mA} \mathrm{~cm}^{-2}$. (a) Comparison of measurement data of a Fe/Cd RFB by Zeng et al. 38] with simulation results using the model developed in the present work for the OCV. Model calculations were performed for the ideal (neglect of activity coefficients) and the real case (activity coefficients from Pitzer model). (b) Estimated ideal and real voltage losses (see Eqs. (35) and (36) of the Fe/Cd RFB investigated by Zeng et al. [38. In addition, the excess OCV calculated using Eq. (3) is shown. 


\section{FIGURES}

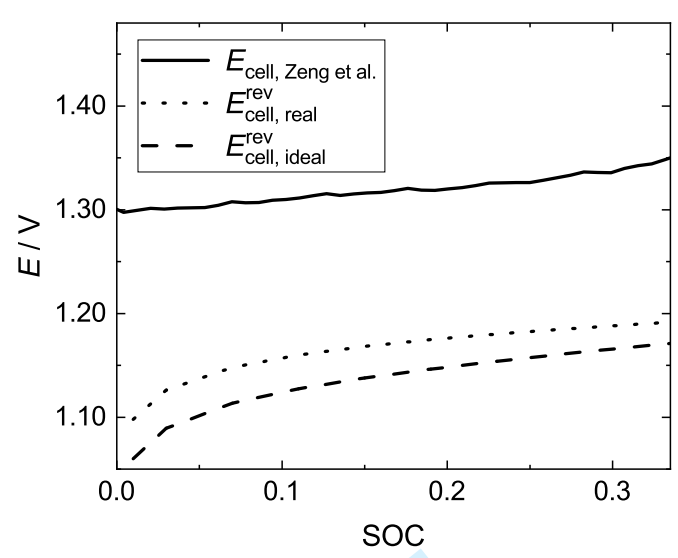

(a)

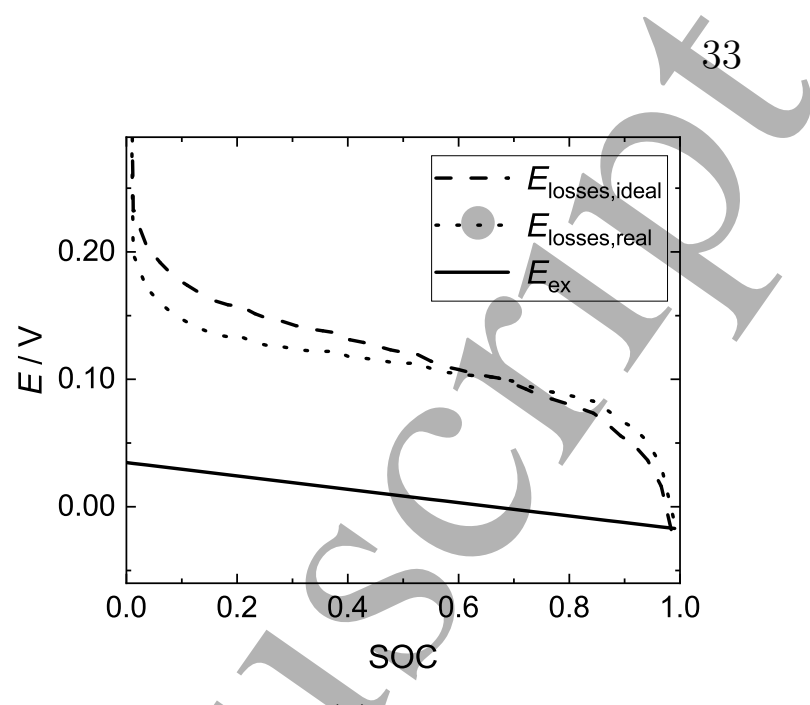

Figure 7. Applied current density: $160 \mathrm{~mA} \mathrm{~cm}^{-2}$. (a) Comparison of measurement data of a Fe/Cd RFB by Zeng et al. 38, with simulation results using the model developed in the present work for the OCV. Model calculations were performed for the ideal (neglect of activity coefficients) and the real case (activity coefficients from,Pitzer model). (b) Estimated ideal and real voltage losses (see Eqs. (35) and (36) of the Fe/Cd RFB investigated by Zeng et al. 38. In addition, the excess OCV calculated using Eq. (3) is shown. 


\section{TABLES}

Table 1. Overview of scenarios studied in the present work.

\begin{tabular}{|c|c|c|c|c|c|}
\hline$\#$ & RFB type & Overall composition & Membrane & Pitzer parameters & Objective \\
\hline 1 & $\mathrm{Fe} / \mathrm{Cd} \mathrm{RFB}$ & $\begin{aligned} \tilde{c}_{\mathrm{FeCl}_{2}}^{0} & =1.0 \mathrm{~mol} \mathrm{l}^{-1} \\
\tilde{c}_{\mathrm{CdCl}_{2}}^{0} & =0.5 \mathrm{~mol} \mathrm{l}^{-1} \\
\tilde{c}_{\mathrm{HCl}}^{0} & =3.0 \mathrm{~mol} \mathrm{l}^{-1}\end{aligned}$ & catex & complete & $\begin{array}{l}\text { Simulation of } E_{\mathrm{ce}}^{\mathrm{re}} \\
\text { with the develop }\end{array}$ \\
\hline $2 \mathrm{a}$ & AVRFB & 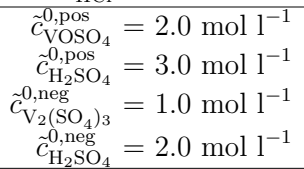 & catex & $\begin{array}{l}\text { unavailable; } \\
\text { no activity based } \\
\text { model used }\end{array}$ & $\begin{array}{l}\text { Simulation of } E_{\text {cell, ideal }}^{\text {rev }} \text { and } \\
\text { comparison with measured } E_{\text {cell, real }}^{\text {rev }} \\
\text { data 37] }\end{array}$ \\
\hline $2 \mathrm{~b}$ & AVRFB & 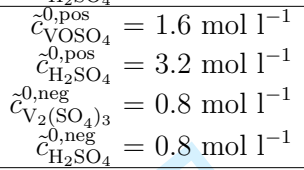 & anex & $\begin{array}{l}\text { unavailable; } \\
\text { no activity based } \\
\text { model used }\end{array}$ & $\begin{array}{l}\text { Simulation of } E_{\text {cell, ideal }}^{\text {rev }} \text { and } \\
\text { comparison with measured } E_{\text {cell, real }}^{\text {rev }} \\
\text { data } 37]\end{array}$ \\
\hline 3 & $\mathrm{Fe} / \mathrm{Cd} \mathrm{RFB}$ & varied & catex & complete & Sensitivity analysis \\
\hline 4 & $\mathrm{Fe} / \mathrm{Cd} \mathrm{RFB}$ & $\begin{aligned} \tilde{c}_{\mathrm{FeCl}_{2}}^{0} & =1.0 \mathrm{~mol} \mathrm{l}^{-1} \\
\tilde{c}_{\mathrm{CdSO}_{4}}^{0} & =0.5 \mathrm{~mol} \mathrm{l}^{-1} \\
\tilde{c}_{\mathrm{HCl}}^{0} & =3.0 \mathrm{~mol} \mathrm{l}^{-1}\end{aligned}$ & catex & $\begin{array}{l}\text { complete } \\
\text { (except } \mathrm{Cd}\left(\mathrm{HSO}_{4}\right.\end{array}$ & $\begin{array}{l}\text { Calculation of voltage losses using } \\
\text { measured } E_{\text {cell }} \text { data [38] }\end{array}$ \\
\hline
\end{tabular}
$\tilde{c}_{\mathrm{HCl}}^{0}=3.0 \mathrm{~mol} \mathrm{l}^{-1}$

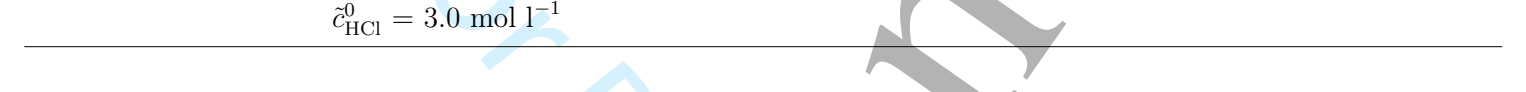

.
5

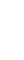
. .

.
.

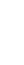
. . . . . 